\title{
A participação do capital e do mercado imobiliário na produção do espaço: os reflexos desse processo na cidade de Vitória da Conquista-BA
}

\section{The participation of capital and the real estate market in the production of space: the reflexes of this process in the city of Vitória da Conquista-BA}

La participación del capital y el mercado inmobiliario en la producción del espacio: los reflejos de este proceso en la ciudad de Vitória da Conquista-BA

\author{
Altemar Amaral Rocha ${ }^{1}$ http://orcid.org/0000-0002-6278-052X
}

\footnotetext{
1 Doutor em Geografia, Analista Universitáio- UESB Professor titular do Departamento de Geografia-UESB- Brasil, altemarrocha@gmail.com
}

\section{Resumo}

Este artigo analisa a participação do capital imobiliário na produção do espaço urbano, buscando demonstrar os reflexos desse processo na cidade de Vitória da Conquista-Bahia, tendo em vista a questão da habitação e da moradia na cidade, especialmente a espacialização das desigualdades existentes entre os bairros, derivadas da concentração da renda e da terra urbana. Traz uma reflexão acerca do conceito de espaço na Geografia, partindo de uma revisão sobre o conceito de produção do espaço. Analisa valorização do espaço e a inversão do valor de uso da moradia, em detrimento da especulação imobiliária. Analisa a consolidação do mercado imobiliário e a questão habitacional da cidade, levando em consideração as implicações desses condicionantes na produção na produção do espaço urbano.

Palavras-chave: Moradia. Mercado imobiliário. Produção do espaço.

\begin{abstract}
This paper analyzes the participation of real estate capital in the production of urban space, seeking to demonstrate the reflexes of this process in the city of Vitória da Conquista-Bahia, considering the issue of housing and housing in the city, especially the spatialization of inequalities between neighborhoods of the city derived from the concentration of income and urban land. It brings a reflection about the concept of space in Geography, starting from a review about the concept of space production. It analyzes the inversion of the value of use of housing, to the detriment of real estate speculation. It analyzes the consolidation of the real estate market and the housing issue of the city, taking into consideration the implications of these constraints on production in the production of urban space.
\end{abstract}

Keywords: Dwelling house. Real estate market. Space production.

\section{Resumen}


Este artículo analiza la participación del capital inmobiliario en la producción de espacio urbano, buscando demostrar los reflejos de este proceso en la ciudad de Vitória da Conquista-Bahía, considerando el tema de la vivienda y la vivienda en la ciudad, especialmente la espacialización de las desigualdades entre barrios de la ciudad derivados de la concentración de ingresos y terrenos urbanos. Trae una reflexión sobre el concepto de espacio en Geografía, a partir de una revisión sobre el concepto de producción espacial. Analiza la inversión del valor del uso de la vivienda, en detrimento de la especulación inmobiliaria. Analiza la consolidación del mercado inmobiliario y el tema de la vivienda de la ciudad, teniendo en cuenta las implicaciones de estas limitaciones en la producción en la producción de espacio urbano.

Palabras clave: Vivienda. Mercado inmobiliario. Producción espacial.

Recebido em: 20/11/2019

Aceito para publicação em: 28/11/2019

\section{Introdução}

A moradia é uma necessidade básica do indivíduo na garantia de sua existência, mas sob o capitalismo essa necessidade é transformada num bem econômico, tendo o seu valor de uso suplantado pelo valor comercial (HARVEY, 2015), nesse contexto o autor afirma que valor de troca da moradia, é determinado pelos custos básicos da construção da casa, porém o construtor agrega outros valores tais como o preço da terra e sua variação ao longo do processo, os juros de financiamento, o tempo de duração da construção, a margem do lucro e o tempo esperado para a venda ou revenda da casa. Assim, Harvey afirma que o objetivo do produtor é obter valor de troca e não valor de uso, o que ocasiona a dificuldade de obtenção da moradia para as classes menos favorecidas economicamente, gerando uma crise habitacional. Rodrigues (2013) argumenta que a crise habitacional está presente sempre que se considera a capacidade de pagar dos compradores. Isso por que o que ocorre não é a falta dessa mercadoria, e sim o valor abusivo muito além do que a grande parcela da população pode pagar. Esta pesquisa leva em consideração o modo pelo qual o indivíduo tem acesso à terra na cidade enquanto condição de moradia, e os princípios que norteiam a produção espacial do urbano em Vitória da Conquista-Bahia.

O espaço urbano de uma cidade deve ser analisado sob uma perspectiva dos processos que engendraram e que engendram o espaço urbano de tal cidade, pois a cidade é um produto da ação humana e como tal não é estático, assume no decorrer do tempo histórico diferentes formas e funções. 
O crescimento das cidades está atrelado a vários fatores, principalmente ao fator econômico. Entretanto o grau de desempenho econômico de uma cidade, normalmente não se traduz em qualidade de vida da população. Ao contrário, o crescimento econômico, muitas vezes representa a pauperização das classes trabalhadoras.

O modo de produção capitalista transformando a terra em mercadoria trouxe uma série de problemas para as cidades, sendo o mais grave o acesso à habitação. Nessa lógica o Poder Público surge como agente reforçador dessa realidade, fazendo com que os maiores investimentos em equipamentos e serviços urbanos coletivos sejam direcionados às áreas privilegiadas, não levando em conta as necessidades da população como um todo.

\section{O mercado imobiliário e sua atuação na produção do espaço urbano}

Recentemente, constatamos a emergência de um mercado imobiliário global pautado na comercialização de imóveis onde a terra é tratada como um simples bem financeiro que segundo Harvey (2013, p. 508), pode ser "comprado e vendido conforme a renda que ele produz”. Para Harvey (2013) Se a terra for livremente comercializada, então ela se torna uma mercadoria de um tipo muito especial. Como a terra não é produto do trabalho, ela não pode ter um valor especifico, neste sentido, o autor afirma: "o que é negociado é um direito sobre as receitas futuras, o que significa um direito sobre os lucros futuros do uso da terra ou, mais diretamente, um direito sobre o trabalho futuro".

A reflexão sobre a "produção do espaço possui exigências teóricas trazidas pelo próprio movimento de reprodução da realidade, com múltiplas configurações, a cidade estrutura-se sob o desígnio da produção e da reprodução do espaço como uma mercadoria" (CARLOS; VOLOCHKO; ALVAREZ, 2015, p. 12). Se é mercadoria esta pode ser comprada e vendida a qualquer momento por qualquer um, pois como afirma Barbosa, (2018, p. 101) "O mercado de cidades exige atratividades diferenciadas para a sua realização como negócio".

Citando Marx, Harvey (2013, p. 508), afirma: A aquisição da terra "simplesmente assegura ao comprador um direito de receber uma renda anual". Para o autor,

Qualquer fluxo de renda (como uma renda anual) pode ser considerado como o juro sobre algum capital fictício, imaginário. Para 
o comprador, a renda aparece em sua contabilidade como o juro sobre o dinheiro investido na aquisição da terra, e em princípio não é diferente de investimentos semelhantes na dívida do governo, nas ações e nas quotas das empresas, na dívida do consumidor e assim por diante. O dinheiro investido é, em todos os casos, capital que rende juros. A terra se torna uma forma de capital fictício e o mercado imobiliário funciona simplesmente como um ramo particular (HARVEY, 2013, p. 508).

Neste sentido, o mercado imobiliário tem um ramo particular que é a comercialização de terras e em particular, terras urbanas. Essa expansão recente da comercialização de terras urbanas pelo mercado imobiliário converteu a urbanização em um processo de mercantilizarão do espaço urbano e acelerou a acumulação do capital privado derivado desse segmento, inclusive com a negociação direta em bolsas de valores de ações e fundos de participação em negócios imobiliários.

Esse processo permitiu o surgimento de inúmeros centros e centralidades urbanas com dinâmicas de venda e revenda da terra pelo mercado imobiliário, como afirma Sanfelici (2016, p. 17) "Os negócios imobiliários têm por fundamento a captura privada de incrementos de rendas que têm origem no processo ininterrupto de reconfiguração das centralidades" urbanas, aumentando ainda mais a dinâmica do capital e como consequência a expansão do capitalismo, tanto no setor imobiliário e nas extrações de renda da terra quanto com base de qualquer outro produto ou bem de consumo. Harvey (2013, p. 14) acrescenta ainda nesse contexto o "capital fixo (particularmente aquele incorporado nos ambientes construídos), as finanças, o crédito, a renda, as relações de espaço e os gastos estatais", para Harvey, tudo isso tem que ser reunido na análise espacial de maneira a compreender melhor os processos urbanos e a participação do setor imobiliário, no desenvolvimento desigual das cidades.

No entanto, é preciso considerar que as especificidades do setor imobiliário, propiciam o incremento de uma parcela significativa de pequenos produtores de habitação no mercado imobiliário atuando tanto no processo de incorporação quanto no segmento de comercialização dos imóveis.

O modo de produção capitalista, transformando a terra em mercadoria, trouxe uma série de problemas para as cidades, sendo o mais grave o acesso à habitação, devido, sobretudo, ao elevado valor da terra e aos baixos salários pagos à população. Engels (1873) aponta que a crise de moradia está diretamente ligada a estrutura produtiva capitalista implantada na Europa do Século XIX, essa estrutura empurrou e 
ainda empurra uma grande massa de trabalhadores a morar em casas de baixo padrão ou na maioria das vezes, viver sem moradia. Assim, "a falta de habitação não é nenhum acaso, é uma instituição necessária e, juntamente com as suas repercussões sobre a saúde, etc, só poderá ser eliminada quando toda a ordem social de que resulta for revolucionada pela base". (ENGELS, 1873, p. 25).

Essa percepção da falta de moradia e habitação, elaborada por Engels, reflete diretamente no contexto espacial da cidade e no modo como o espaço é produzido, ou seja, cada transformação ocorrida ao longo do processo de urbanização implicará na produção de "espaços diferenciados, com conteúdos diversos". Nesse sentido, "o espaço geográfico é um produto de relações concretas que o homem cria na sociedade e através dela", (CARLOS, 1994, p. 35).

Portanto, na busca de se analisar o espaço urbano de uma determinada cidade, neste caso o de Vitória da Conquista, é preciso compreender o movimento de produção e reprodução da própria sociedade, pois como coloca Carlos, (1994, p. 33), "na medida em que a sociedade produz e reproduz sua existência de um modo determinado, este modo imprimirá características históricas específicas". Esta especificidade é entendida por Lefebvre (2013), como singularidade.

Para Lefebvre cada lugar é singular, pois possui uma forma e uma realidade física que o distingue dos demais, mas também é universal, na medida em que se relaciona por meio das forças produtivas e das relações de produção com a lógica que desencadeia o processo de produção espacial.

Neste contexto, pode se dizer que o espaço urbano é produto das relações sociais, e das formas dessas relações. Na maioria das vezes essas relações são conflitantes e, o espaço urbano demonstra em suas formas todo esse conflito de classes e interesses que existe, por meio da diferenciação espacial, tais espaços diferenciados numa cidade demonstram a desigualdade com que a apropriação do espaço ocorre na atual sociedade, pautada nos moldes do capitalismo.

É suficiente observar qualquer cidade para verificar que há uma grande diferenciação entre as características de moradias dos bairros, tamanho dos lotes das construções, da "conservação", de acabamento das casas, as ruas-asfaltadas ou não -, a segregação espacial. Ao mesmo tempo, há espaços na cidade com infraestrutura e outros sem. [...] Isto significa que a diversidade não se refere apenas ao tamanho e características das casas e terrenos, mas à própria cidade (RODRIGUES, 1988, p. 11). 
O modo pelo qual o indivíduo terá acesso à terra na cidade enquanto condição de moradia, vai depender do modo pelo qual a sociedade estiver hierarquizada em classes sociais e de conflito entre parcelas da população. Como aponta Carlos (1997 p. 54) ao colocar que “(...) o tipo, local, tamanho e forma de moradia vão depender e expressar o modo como cada indivíduo se insere dentro do processo de produção material geral da sociedade".

Trazendo essa reflexão para a questão urbana da cidade de Vitória da ConquistaBA, pode-se dizer que nos últimos anos o mercado imobiliário tem atuado com força na produção do espaço urbano da cidade e nesse processo acentuam-se as desigualdades socioespaciais em um ritmo cada vez mais acelerado e hierarquizado.

\section{Valorização e financeirização da moradia como formas de produção do espaço urbano}

A lógica de valorização capitalista do espaço pode ser explicada pelo avanço da "financeiriação da cidade" (VOLOCHKO, 2007), pela subversão do papel da moradia que possui valor de uso e, nesse processo passa a ser moeda com valor de troca. Numa cidade onde há uma intensa valorização espacial, a população sofrerá ainda mais com a dificuldade de obter acesso a uma moradia digna, principalmente no caso Brasil em que grande parcela da população recebe salários baixos e insuficientes para atender a todas as necessidades humanas, como educação de qualidade, saúde, alimentação, vestuário, etc. e, principalmente, o acesso à moradia.

Numa sociedade de classes a possibilidade de acesso à terra urbana será sempre desigual e contraditório. Nesse processo a população mais pobre, por não possuir renda suficiente para adquirir uma moradia num local dotado de uma boa estrutura urbana, se vê obrigada a residir em bairros distantes e precários. Além disso, as condições da moradia, ou seja, as características das casas variam muito de acordo com a realidade econômica da população.

Em Vitória da Conquista-BA, percebe-se que o individuo enquanto sujeito da ação social está cada vez mais deslocado do acesso à moradia, já que o preço da terra na cidade é elevado e concentrado nas mãos de poucos, pois como afirma Harvey (2015 p. 175) O solo urbano e o mercado imobiliário são lugares fecundos para uma classe rentista próspera acumular ainda mais riqueza e poder. Observa-se que quanto mais valorizado o solo urbano mais elitizado se torna o lugar é o caso do Bairro Candeias 
onde o preço do metro quadrado é um dos mais caros da cidade e também é o bairro onde há uma maior concentração de renda ver (mapa 1)

Constata-se conforme os dados do mapa 1 que há uma estreita relação entre o poder aquisitivo e padrão de moradia e valorização dos imóveis e terrenos, percebe-se que há uma concentração de renda maior nos Bairros Recreio e Candeias e essa concentração coincide com o aumento do valor venal dos imóveis.

Mapa 1- Valor Venal, Verticalização e rendimento por setor censitário- Vitória da Conquista-BA - 2019.

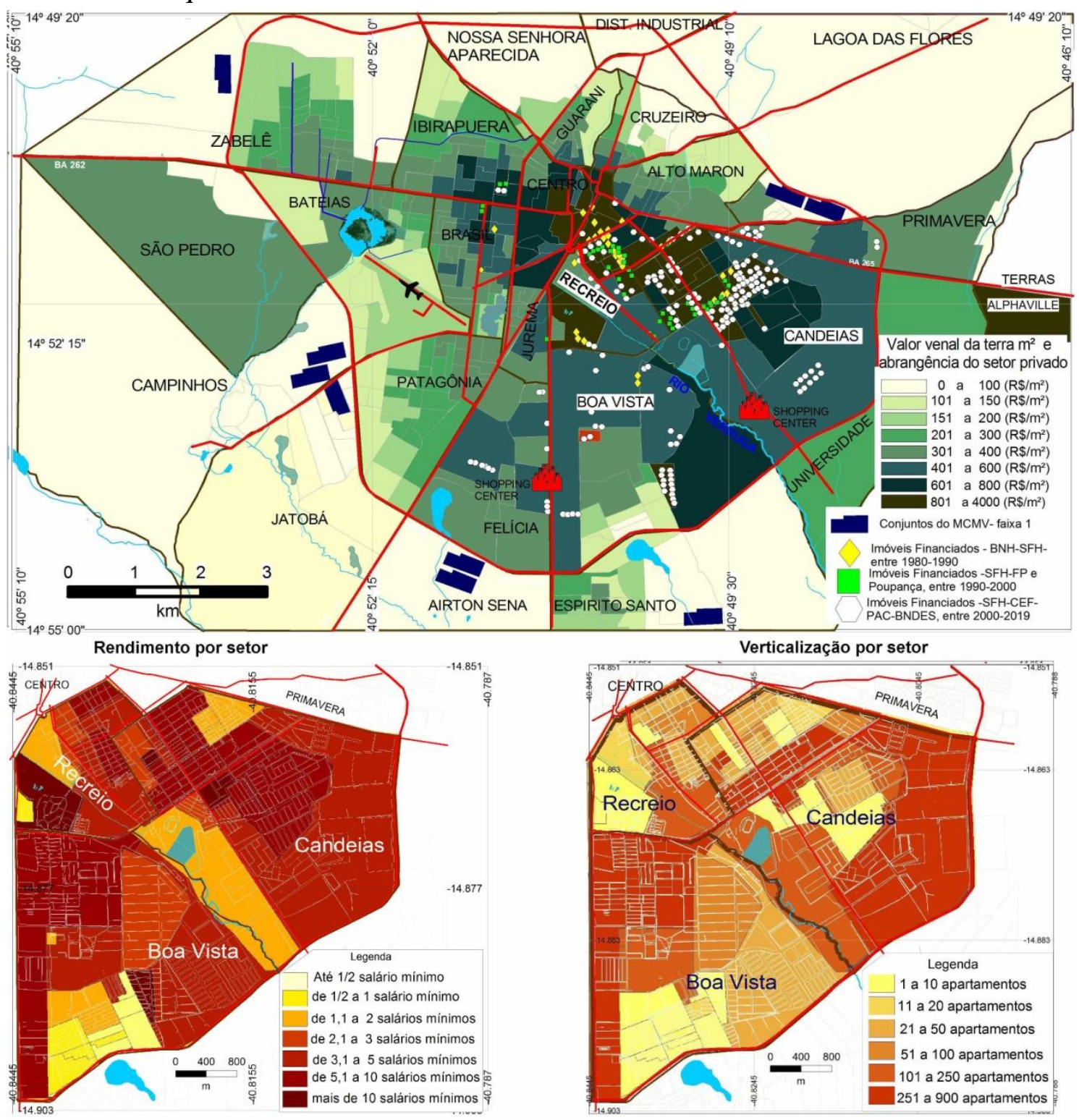

Fonte: Elaborado por Rocha (2019), com dados do Atlas geográfico de Vitória da Conquista-BA, dados do IBGE, 2010, dados da pesquisa de campo entre 2013 a 2019. 
Com base no (mapa 1), outra questão que pode ser analisada é a expansão da verticalização na Cidade de Vitória da Conquista. Percebe-se que ela concentra especificamente nos Bairros Recreio e Candeias com uma recente expansão para o Bairro Boa Vista. Conforme os dados do IBGE (2010), a cidade nessa época possuía cerca de 5000 unidades de apartamentos na modalidade verticalizada hoje conforme o levantamento de pesquisa de campo (2019) os dados apontam que já são mais de 10.000 unidades de apartamentos do tipo edificação verticalizadas com um ou mais andares. Essa verticalização recente, concentrou-se basicamente no entorno da Avenida Olivia Flores e da Avenida Luís Eduardo Magalhães com pode ser observado no mapa 2, o número maior de imóveis financiados por algum órgão de manutenção das políticas nacionais de habitação estão neste trecho

Mapa 2 - Espacialização dos produtos do mercado imobiliário de acordo a origem do financiamento - Vitória da Conquista-BA- 2019

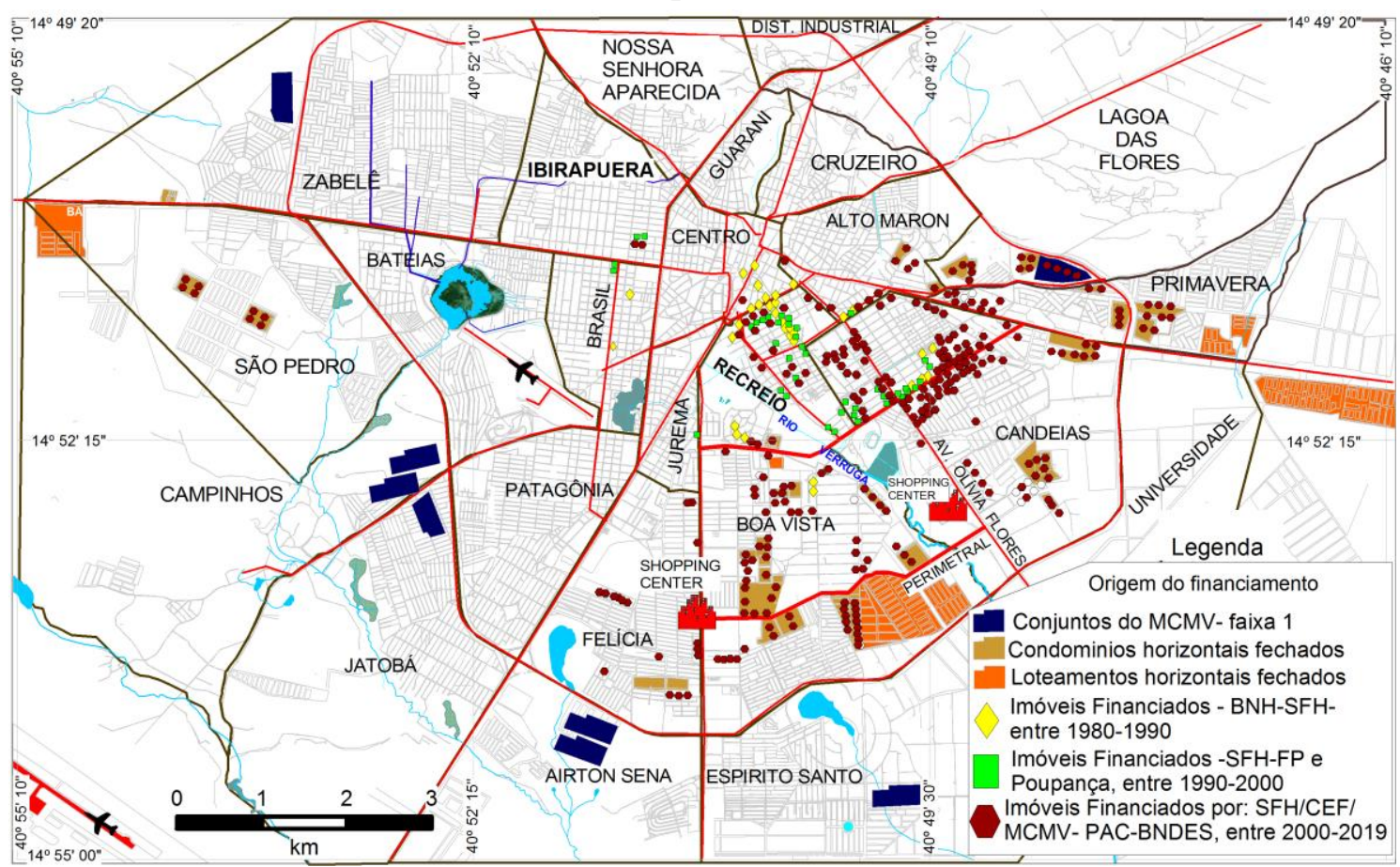

Fonte: Elaborado por Rocha (2019), pesquisa de campo (2013 a 2019)

Há outra consideração que precisa ser feita é que os bairros Recreio e Candeias são historicamente ocupados por uma classe alta e média alta, Rocha (2013) e Ferraz (2001), apontam que estes bairros tiveram sua origem na década de 1970 para atender uma demanda de crescimento populacional que Vitória da Conquista viveu entre os anos de 1960 e 1970. Ou seja, tais bairros foram paulatinamente sendo convertidos em 
áreas nobres da cidade pela destinação de moradores de famílias tradicionais da cidade que migraram do centro para os bairros Recreio e Candeias.

A valorização foi sendo aos poucos consolidada pelo adensamento das edificações, pelo tamanho maior dos lotes disponíveis para venda, tamanho das edificações construídas, o impacto da vizinhança, tudo isso propiciou uma forma a manter o grau de elitização dessas áreas, mesmo com as políticas habitacionais de assentamento popular no seu entorno, como é o caso das Urbis I, do conjunto BNH, dos conjuntos do Inocoop entre outros, tais conjuntos habitacionais foram massivamente convertidos e incorporados ao padrão predominante nos bairros que é de classe média a alta.

Por outro lado, verifica-se que há um processo de valorização associado ao adensamento urbano, ou seja, na medida em que os novos empreendimentos vão sendo incorporados, esses espaços passam por um processo de aceleração do valor venal do $\mathrm{m}^{2}$ de terrenos vagos para novas construções. Essa tendência de valorização é perceptível no entorno da Av. Olivia Flores Com a construção do Shopping Boulevard e com a abertura da Avenida Perimetral José Pedral Sampaio. (mapas 1 e 2)

É preciso considerar que a trajetória de valorização tem uma origem desde a década de 1980 e estende-se pelos anos 2000, com a criação de novos loteamentos, com o lançamento de grandes empreendimentos urbanos, associados à implantação de equipamentos públicos, tais como universidades públicas e privadas, grandes avenidas; Shoppings; agências bancárias e outros serviços especializados.

Gráfico 1 - Percentual da participação de loteadoras no mercado imobiliário por número de lotes em loteamentos fechados - área legal da cidade de Vitória da ConquistaBA, 2019.

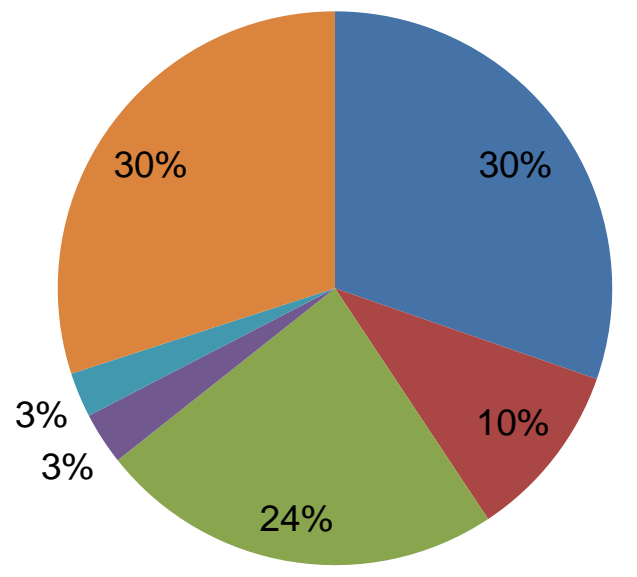

\author{
Terras Aphaville \\ - Horto Premier + Lago Preimer \\ - Parque dos Ipês I e II \\ Vila Constanza \\ Parque das águas \\ Outros
}

Fonte: pesquisa de campo (2019) 
Assim pode-se dizer que a curva de valorização do $\mathrm{m}^{2}$ nesses bairros persiste por mais de 30 anos e vem se consolidando fortemente nos últimos cinco anos com a chegada de várias incorporadoras e construtoras na cidade. Essas incorporadoras atuam tanto na abertura de loteamentos, quanto na construção de habitações para moradia. No (gráfico 1), temos uma distribuição do percentual de unidades loteadas em condomínios fechados por incorporadoras.

Percebe-se que é neste momento então que o capital Financeiro, em parceria com o capital imobiliário insere de vez no espaço urbano de Vitória da Conquista, com a chegada de empresas de capital misto tais como a Terras Alphaville e MRV que possuem uma participação massiva do capital internacional com negociação direta de ações na Bolsa de Valores e a negociação de fundos imobiliários. No entanto, há uma diferença marcante entre as duas empresas, a MRV, além de atuar como loteadora com a criação do Land Bank, é também incorporadora e construtora. Já a Alphaville atuam apenas como loteadora com mais de 60 loteamentos residenciais e comerciais em todo o País. (INFORMAÇÃO VERBAL) ${ }^{2}$

A Alphaville urbanismo investiu 74 (setenta e quatro) milhões de reais para a compra fundiária, implantação da infraestrutura e mobilidade dos loteamentos de luxo em Vitória da Conquista, para um ganho em longo prazo de 150 milhões de reais, porém na conjuntura nacional a empresa vem amargando nos últimos dois anos um prejuízo de cerca de $50 \%$ do seu patrimônio liquido, segundo dados da própria empresa são mais de $\mathrm{R} \$ 937$ milhões de reais em prejuízo em 2017 e 2018 consecutivamente (INFORMAÇÃO VERBAL) ${ }^{3}$.

Já a MRV engenharia, investiu bem menos em Vitória da Conquista, ao todo foi investido pouco mais de 2 (dois milhões de reais) com ganhos acima da média de mercado para a empresa. Segundo dados da MRV (2019), a empresa atua hoje em mais de 160 cidades brasileiras, "isso faz com a empresa tenha um mercado endereçável potencial de mais de 300.000 moradias por ano "(informação verbal) ${ }^{4}$. Este é um bolo muito grande e a MRV quer ter um share, afirma Menin (2019) "esse é o nosso projeto,

\footnotetext{
${ }^{2}$ Extraído de alphavilleurbanismo S.A. em 13 de novembro de 2019, disponível em: https://www.alphavilleurbanismo. com.br/linha-de-produtos

${ }^{3}$ Balanco anual da empresa Alphavile urbanismo S.A, com demonstrações financeiras em 31 de dezembro de 2018 e 2017

${ }^{4}$ Transcrição de conferencia entre diretores da MRV, em 13 de novembro de 2019, disponível em

https://ri.mrv.com.br/ListResultados/Central-de-Resultados?=r0Kr7/51+2K3bi4bQ2t63g==acesso 15 de dezembro de 2019 
de ter um share de aproximadamente $20 \%$ desse mercado" (INFORMAÇÃO VERBAL) ${ }^{5}$.

Com a fala do dono da empresa percebe-se não há o menor interesse em resolver o problema da moradia para a população pobre. Na visão do empresário o seu negócio é o lucro, mesmo que a qualidade das casas não seja prioridade. Para a MRV, os investimentos e linhas de financiamentos variam desde o Sistema Brasileiro de Poupança e Empréstimo (SBPE) que vem dos rendimentos das poupanças; do Programa minha casa Minha Vida (MCMV), direto da Caixa, pelo sistema IPCA ou pelo sistema SBPE/TR. Além disso, a empresa criou recentemente um sistema denominado por ela de Land Bank, ou seja, Banco de Terrenos para compra e venda direta, tanto pela empresa quanto por outros grupos interessados em construir, como é o caso da Luggo, empresa de fundos imobiliários, startup da MRV, que firmou parceria com a empresa para construir e alugar imóveis em várias cidades do Sul e Sudeste do País.

Essas negociações começam a fazer parte do cenário da construção civil da cidade que, até pouco tempo era comanda por empresas locais e ou regionais como é o caso da Prates Bomfim, Ciclo engenharia, E2 engenharia, Pel construtora, Gráfico Empreendimentos imobiliários entre outras. Com base nos dados do (gráfico 1) pode-se perceber que o percentual é bem homogêneo entre as empresas que controlam o mercado imobiliário de Vitória da Conquista, juntas as seis maiores empresas controlam $82 \%$ do mercado.

Gráfico 1 - Percentual de participação das incorporadoras no mercado imobiliário por número de unidades construídas na cidade de Vitória da Conquista-BA, 2019

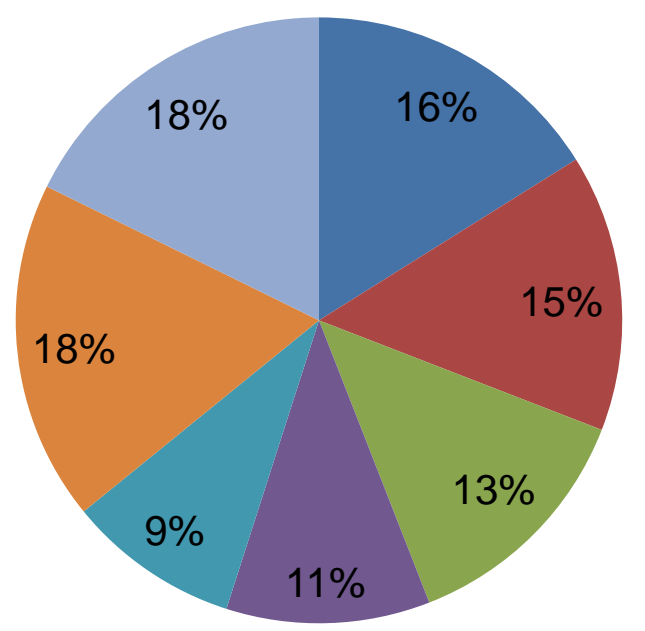

- Gráfico Empreendimentos

- PEL Construtora

MRV

- VCA Construtora

E2engenharia

- Kubo Engenharia/Prates Bonfim

Fonte: pesquisa de campo (2019).

\footnotetext{
${ }^{5}$ Idem

V. 3, no 4, Especial, 2019 http://periodicos2.uesb.br/index.php/geo
}

Este é um artigo de acesso aberto sob a licença Creative Commons da CC BY 
Hoje a participação dessas empresas é bem representativa pela quantidade de unidades produzidas, de um total de 10.000 (dez mil) unidades produzidas em condomínios fechados e conjuntos residenciais verticais nos últimos oito anos, a Kubo Engenharia e Gráfico Empreendimentos, foram as que mais construíram na cidade, seguidas pela Pel Construtora, MRV, VCA, e E2engenharia.

Se durante todo o século XX, a maioria das casas de Vitória da Conquista foram construídas na forma de autoconstrução, agora com o financiamento do programa Minha Casa Minha Vida e com as demais modalidades de financiamento habitacional, as edificações passaram a ser realizadas em sua maioria pelas incorporadoras e construtoras que controlam todos os novos empreendimentos imobiliários na cidade e com os ganhos obtidos nesse processo, refinanciam as novas construções e ou novas aquisições de terrenos para manter o ciclo de acumulação em constante expansão.

No entorno dessa área consolidada do Bairro Candeias existia e ainda existe um estoque de terrenos relativamente grande, seja pelos desmembramentos e reloteamentos que ocorrem no próprio bairro seja por grandes áreas ocupadas por pastagens no entorno do Rio Verruga entre os Bairros Boa Vista e Candeias(ROCHA, 2018), o fato é que nessas áreas houve uma crescente implantação de condomínios horizontais fechados, aliada a uma crescente implantação de loteamentos fechados e uma rápida verticalização com edifícios de médio e alto padrão, sobretudo no entorno da Av. Luís Eduardo Magalhães e no entorno da Av. Olívia Flores. Os dados do (gráfico 2), ilustram a participação de algumas empresas no processo de criação de loteamentos fechados na cidade.

Nos últimos anos, sobretudo entre 2010 e 2019, a participação do capital imobiliário, subsidiado e financiado pelo Estado, tem absorvido boa parte dos valores destinados à construção habitacional. Outra parcela significativa destes investimentos vem dos lucros obtidos com os empreendimentos imobiliários privados associados a outras fontes de financiamento, que vão desde os lucros obtidos em ações negociadas no mercado financeiro ou por lucros do setor produtivo, além dos investimentos obtidos com a venda de propriedades rurais, com a venda de commodities; investimentos associados a fundos imobiliários ou fundos de renda fixa.

Enfim, esses investimentos controlam quase a toda a produção habitacional na cidade, empurra a população pobre cada vez mais para as áreas de submoradia, diminuindo as chances de acesso a moradia por uma parcela significativa da população. 
Neste processo Constata-se que houve uma inversão nos padrões de construção da moradia, se antes o trabalhador comprava um terreno e iniciava a sua casa no sistema de autoconstrução, agora, a compra do terreno tornou-se cada vez mais difícil, na medida em que os valores praticados no mercado são destinados a uma faixa de renda acima de três salários mínimos e esse percentual de rendimento é bem reduzido entre os 338.480 habitantes de Vitória da Conquista (IBGE, 2019).

\section{Considerações finais}

Pode-se apontar aqui algumas considerações sobre a relação existente entre a produção dos imóveis patrocinados pelo sistema financeiro e produzidos por empresas de capital misto e de capital multinacional com a questão da produção do espaço, da valorização dos eixos de crescimento e expansão urbana da cidade de Vitória da Conquista é o caso das Terras do empreendimento Alphaville que segundo dados da empresa, foram investidos mais de 70 milhões de reais para a compra de terrenos, implantação da infraestrutura e montagem do padrão de urbanização, requerido pela empresa e pelos investidores. Um dos principais investimentos realizados pela empresa foi a construção de uma via de acesso entre o condomínio Terras Alphaville e a Av. Olivia Flores, este foi também um dos pilares do marketing de vendas dos mais de mil lotes colocados à venda pela empresa.

Outra área que também passou por estratégia recente de valorização para o capital imobiliário foram as extensas faixas de terras de uso agrário entre a Av. Olivia Flores e o Rio Verruga, nos Bairros Candeias e Boa Vista.

Nessas terras, os proprietários fundiários, associaram-se com empresas locais, com empresas regionais e, com o poder público para garantir de um lado, a infraestrutura urbanística do local e de outro, elevar o valor venal de suas terras com a implantação de equipamentos de grande monta, tais como o shopping Boulevard, grandes centros comerciais e condomínios fechados. Assim, "o espaço é entendido não mais apenas como matéria-prima e meio de produção, mas como produto possuidor de valor e que se valoriza segundo dinâmicas propriamente urbano-espaciais e financeiras" (CARLOS; VOLOCHKO; ALVAREZ, 2016, p. 11).

Configura-se assim um grande movimento que envolve estratégias de marqueting imobiliário, aliado ao portfólio de venda da empresa com estratégias de financiamento que vão atraindo uma classe consumidora que encaixa no perfil de venda 
nas faixas de financiamento dos bancos, mais especificamente as faixas de Renda definidas pelo Programa Minha Casa Minha Vida e subsidiada pelo Governo Federal através da Caixa Econômica Federal.

Essas estratégias de empreendimento imobiliário promove de um lado um rápido processo de urbanização em áreas que até pouco tempo funcionava como pastagem para o gado porem ao mesmo tempo fragmenta cada vez mais o espaço urbano pela adoção de praticas de cercamento e muro dos condomínios fechados que é o carro chefe dos novos empreendimentos imobiliários desenvolvidos pelas empresas que estão diretamente ligadas ao capital financeiro e capital internacional.

A fragmentação urbana é cada vez maior no entorno da Avenida Perimetral, no entorno da Avenida Gilenilda Alves e no entorno da Av. Luis Eduardo Magalhães. Se antes o Rio Verruga era uma fonte natural de fragmentação do espaço urbano de Vitória da Conquista agora além do Rio Verruga, os mais de 40 (quarenta) novos Condomínios Fechados já instalados na cidade fragmentam ainda mais os bairros e loteamentos dessa região, dificultando o acesso aos principais equipamentos públicos que estão no entorno da Avenida Olivia Flores. Neste contexto, a expansão dos condomínios e loteamentos fechados engendra uma "fragmentação ainda maior do espaço e instituem novos mecanismos tanto de espoliação quanto de integração precária dos pobres ao urbano". (VOLOCHKO, 2015, p. 11).

Por outro lado, o poder público municipal garante a implantação das vias de acesso tais como a Avenida Perimetral e Av. Luis Eduardo Magalhães, seguida pelo embelezamento da Av. Olivia Flores e seu entorno. De outro, o setor imobiliário fragmenta ainda mais este espaço com a implantação de diversos condomínios fechados do tipo alto padrão, constituindo-se assim numa rápida transformação de uma grande área recém-loteada e fechada, rateada entre empresas construtoras/incorporadoras que visam o desenvolvimento de grandes projetos imobiliários, em sua maioria, financiados pelas políticas habitacionais vigentes, aumentando as desigualdades socioespaciais da cidade, na medida em que o acesso a esses bens e serviços recém-implantados está restrito a uma pequena parcela da sociedade que pode pagar por esses novos "produtos" também chamados de novos "conceitos de padrão de moradia" vendidos pelo mercado imobiliário. Pois como afirma Botelho (2007), com muito dinheiro nas mãos, a classe mais rica pode: ocupar, modelar, fragmentar o espaço da forma que melhor lhe convém. 
ROCHA, A. A.

Neste sentido, a maximização dos valores de troca produz benefícios desproporcionais para alguns grupos e diminui as oportunidades para outros.

\section{Referências}

ALPHAVILLE URBANISMO S.A. relatório com demonstrações financeiras em 31 de dezembro de 2018, São Paulo: KPMG, 2019.

BARBOSA, Jorge Luiz. "Por uma cartografia de microutopias para reinvenção da cidade.” In: CARLOS, A. F. A.; SERPA, A. Geografia Urbana: Desafios Teóricos Contemporâneos, DGO - Digital original ed., SciELO - EDUFBA, 2018, pp. 95-111.

BOTELHO, A. A cidade como negócio: produção do espaço e acumulação do capital no município de São Paulo, Cadernos Metrópoles, nº 18, São Paulo, Pucsp, 2007

CARLOS, A. F. A; VOLOCHKO, D.; ALVAREZ, P. I. (org.).A cidade como negócio. São Paulo: Contexto, 2015.

CARLOS, A. F. A. A cidade. 3 ed. São Paulo: Contexto, 1997

CARloS, A. F. A. A (Re)Produção do Espaço Urbano. São Paulo: Editora da Universidade de São Paulo, FFLG-USP, 1994.

ENGELS. F. [1873].Para a questão da habitação. Lisboa: Editorial Avante, 1987.

FERRAZ, A. E. de Q. O urbano em construção, um retrato de duas décadas, Vitória da Conquista: Edições UESB, 2001.

HARVEY, D. 17 contradições e o fim do capitalismo. Tradução Rogério Bettoni. São Paulo: Boitempo, 2015.

HARVEY D. Os limites do capital. Trad. Magda Lopes, São Paulo: Boitempo, 2013.

IBGE. Estimativas da população 2019, Rio de Janeiro, IBGE, 2019, disponível em: https://www.ibge.gov.br/estatisticas/sociais/populacao/9103-estimativas-de populacao.html $?=\& \mathrm{t}=$ resultados, acesso em 30 de novembro de 2019

IBGE. Censo demográfico 2010, Rio de Janeiro, IBGE, 2019, disponível em: https://www.ibge.gov.br/estatisticas/sociais/populacao/9103-estimativas-de populacao.html $?=\& \mathrm{t}=$ resultados acesso em 30 de novembro de 2019

LEFEBVRE, H. La producción del espacio. Trad. Emilio Martínez Gutiérrez, Madrid: Capitain Swing, 2013;

MRV, divulgação de resultados, transcrição call Conference, 13 de novembro de 2019. Belo Horizonte, MRV, 2019. Disponível em: https://ri.mrv.com.br/ ListResultados /Central-de Resultados?=r0Kr7/51+2K3bi4bQ2t63g==, acesso em 29 de novembro de 2019. 
ROCHA, A. A.

ROCHA, A. A. O papel de João Gonçalves da Costa na produção do espaço baiano entre os séculos xviii e xix: as origens do território de Vitória da Conquista. Geopauta, [S.1.], v. 2, n. 3, p. 83-99, dez. 2018. ISSN 2594-5033. Disponível em:

<http://periodicos2.uesb.br/index.php/geo/article/view/3732>. Acesso em: 30 nov. 2019. doi: https://doi.org/10.22481/rg.v2i3.3732.

ROCHA, A. A. Os processos de planificação territorial e transformações socioespaciais em Vitória da Conquista-BA. 2013. Tese. (Doutorado em Geografia) Programa de Pós Graduação em Planificacion Territorial e Gestion Ambiental da Universidad de Barcelona- UB. Barcelona, 2013.

ROCHA, A. A.; FERRAZ, A. E. de Q. Atlas Geográfico de Vitória da Conquista. Vitória da Conquista: Edição dos autores, 2015.

RODRIGUES, A. M. Loteamentos murados e condomínios fechados: propriedade fundiária urbana e segregação socioespacial. In: VASCONCELOS, P. de A.; CORREA, R. L.; PINTAUDI, S.M. (Org.). A cidade contemporânea: segregação espacial. São Paulo: Contexto, 2013, p. 147-168.

RODRIGUES, A. M. Moradia nas cidades brasileiras. São Paulo: Contexto, 1998.

SANFELICI, D. Centralização do capital no setor imobiliário e reconfiguração das metrópoles, Mercator, Fortaleza, v. 15, n.2, p.7-21, abr./jun., 2016.

VOLOCHKO, D. A moradia como negócio e valorização do espaço urbano metropolitano. In: CARLOS, A. F. A; VOLOCHKO, D.; ALVAREZ, P. I. (org.).A cidade como negócio. São Paulo: Contexto, 2015.

VOLOCHKO, D. A produção do espaço e as estratégias reprodutivas do capital: negócios imobiliários e financeiros em São Paulo. 2007. Dissertação (mestrado em geografia humana) Programa de Pós-Graduação em Geografia Humana, Faculdade de Filosofia, letras e ciências humanas da USP, São Paulo, 2007. 